\title{
Needs of patients with dementia and their caregivers in primary care: lessons learned from the Alzheimer plan of Quebec
}

\author{
Vladimir Khanassov ${ }^{1 *}$, Laura Rojas-Rozo², Rosa Sourial ${ }^{3}$, Xin Qiang Yang ${ }^{3}$ and Isabelle Vedel ${ }^{2,3}$
}

\begin{abstract}
Background: Persons living with dementia have various health and social care needs and expectations, some which are not fully met by health providers, including primary care clinicians. The Quebec Alzheimer plan, implemented in 2014, aimed to cover these needs, but there is no research on the effect this plan had on the needs and expectations of persons living with dementia. The objective of this study is to identify persons living with dementia and caregivers' met and unmet needs and to describe their experience.
\end{abstract}

Methods: This is a sequential mixed methods explanatory design: Phase 1: cross-sectional study to describe the met and unmet health and social care needs of community-dwelling persons living with dementia using Camberwell Assessment of Need of the Elderly and Carers' Assessment for Dementia tools. Phase 2: qualitative descriptive study to explore and understand the experiences of persons living with dementia and caregivers with the use of social and healthcare services, using semi-structured interviews. Data from phase 1 was analyzed with descriptive statistics, and from phase 2, with inductive thematic analysis. Results from phases 1 and 2 were compared, contrasted and interpreted together.

Results: The mean total number of needs reported by the patients was 5.03 (4.48 and 0.55 met and unmet needs, respectively). Caregivers had 0.52 met needs (3.16 unmet needs). The main needs for both were memory, physical health, eyesight/hearing/communication, medication, looking after home, money/budgeting. Three categories were mentioned by the participants: Persons living with dementia and caregiver's attitude towards memory decline, their perception of community health services and of the family medicine practice.

Conclusions: Our study confirms the findings of other studies on the most common unmet needs of the patients and caregivers that are met partially or not at all. In addition, the participants were satisfied with access to care, and medical services in primary practices, being confident in their family. Our results indicate persons living with dementia and their caregivers need a contact person, a clear explanation of their dementia diagnosis, a care plan, written information on available services, and support for the caregivers.

Keywords: Dementia, primary healthcare, family medicine practice, needs, expectations, Quebec Alzheimer Plan original author(s) and the source, provide a link to the Creative Commons licence, and indicate if changes were made. The images or other third party material in this article are included in the article's Creative Commons licence, unless indicated otherwise in a credit line to the material. If material is not included in the article's Creative Commons licence and your intended use is not permitted by statutory regulation or exceeds the permitted use, you will need to obtain permission directly from the copyright holder. To view a copy of this licence, visit http://creativecommons.org/licenses/by/4.0/. The Creative Commons Public Domain Dedication waiver (http://creativeco mmons.org/publicdomain/zero/1.0/) applies to the data made available in this article, unless otherwise stated in a credit line to the data. 


\section{Background}

Alzheimer's disease and other related dementias has been recognized by the World Health Organization as the "global public health crisis of the 21 st century" $[1,2]$. Dementia is a neurodegenerative disorder characterized by decline in memory and cognitive functions that interfere with activities of daily living of individuals [3]. It is reported that every four seconds a new case of dementia is detected in the world (7.7 million new cases each year) [1].

\section{Needs of the patients living with dementia and their caregivers}

Persons living with dementia (PWD) have various needs and expectations, some of them are not yet fully met (e.g., early diagnosis of dementia) [4]. The abbreviation of PWD is only used for the convenience of the article and to respect the word limits. Family caregivers are still the main source of help to this population and often report physical and psychological burden [5]. They are involved in the day-to-day care in addition to coordinating a variety of health services. One of the recent studies showed that more than $70 \%$ of caregivers had at least one unmet need that is underestimated by the healthcare system [6, 7].

\section{Role of primary care}

PWD and their caregivers require a variety of interventions based on their health and social needs. However, a consistent and widespread criticism of the care received by PWD and their families in many countries is that it is fragmented and rarely person-centered [8]. There are different models of dementia patient-centered care but not routinely implemented in primary care (e.g., case management) [9-15].

Thus, it is imperative to restructure the healthcare system to deliver person-centered care able to address the multiple needs of this population.

A comprehensive systematic review has described the variety of the needs of PWD living in the community (e.g., assistance with daily activities, safety, access to FPs) and caregivers (emotional support, education on the diagnosis, advance care planning) as well as the impact of the intervention focused on the needs of these vulnerable populations - case management (e.g., better education on the disease, provision of sufficient information on dementia-specific community resources) [4].

Five Canadian consensus conferences on Alzheimer's disease have recommended that prevention-promotion, detection, diagnosis and treatment of patients should predominantly be under the responsibility of primary care $[16,17]$. The best chance to address the health care demand driven by dementia is to get primary care involved early in the disease process [18]. However, the primary care system is not yet prepared to face the growing prevalence of this disease and to provide patientcentered care [19-22]. Thus, the majority of patients does not receive a diagnosis of dementia or the appropriate service in primary care [23]. In addition, the primary healthcare professionals tend to underestimate the impact of the disease on the caregivers [24]. In response, Canadian governments (e.g., Ontario [25], Quebec [26]) have developed their provincial programs.

The Quebec Ministry of Health implemented in 2014 the Quebec Alzheimer Plan [27] (hereafter, the Plan) in all Family Medicine Practices (FMP) [28]. According to the Plan, family physicians (FP) of FMP are responsible for the diagnosis of dementia, management of the memory decline and behavioral symptoms associated with dementia, treatment and support of caregivers [26]. FPs refer PWD to the specialized care services (e.g., memory clinic, geriatrics, neurology) when they need a comanagement of complex cases or for an advice on other options of the treatment (e.g., poorly controlled behavioral symptoms, rapidly progressive memory decline, early onset of dementia). FPs work in close collaboration with a nurse (a case manager) who provides timely followups, updates the treating physician on any change in the condition of PWD as well as connect the caregivers with the community support services (e.g., local Alzheimer society chapter). FPs and the nurses use a protocol on dementia investigation, pharmacologic and non-pharmacologic treatment and caregivers support [29, 30].

While there was no formal study focusing on the PWD and caregivers needs evaluation prior to the Plan implementation, a retrospective study on the impact on the Plan showed a significant improvement of the frequency and quality of follow-up of PWD after the Plan implementation [27].

Consequently, research is required to understand how the Plan has impacted the health and social response to the needs of PWD and their caregivers as well as their perceptions of the received services. Thus, the objective of this study is to identify PWDs' and caregivers' met and unmet needs and to describe their experience within the context of the Plan implementation.

\section{Methods}

This is a sequential mixed methods explanatory design [31] composed of a cross-sectional quantitative study (Phase 1) to describe the met and unmet health and social care needs of community-dwelling PWD and their caregivers, followed by a qualitative descriptive study (Phase 2) to further explore and understand their experience. We integrated the quantitative and qualitative 
results to identify how the needs of PWD and their caregivers are met (or unmet).

\section{Participants and setting}

This study was conducted in three FMPs in Montreal, Quebec. All three sites are the teaching facilities for the residents. FMPs provided a list of the patients with the diagnosis of dementia (code 08 as per provincial administrative data-base nomenclature). Based on the list, we identified persons with a diagnosis of dementia or mild cognitive impairment (Mini-Mental State Examination (MMSE) (score above 10) and the Montreal Cognitive Assessment (MoCA) (score above 3) as reported in the patient's chart); able to speak French or English; community dwelling; who have an informal caregiver (caregiver hereafter); and who were able to consent, report feelings, and express concerns regarding the disease [32].. For the caregivers, we selected persons knowledgeable about the PWD, and who spent a minimum of 4 hours (unpaid) per day [33]; who were the primary contact in the patient's medical record; and who routinely accompanies the PWD to the FP. All participants signed consent forms for each phase of the study. We recruited a total of 29 PWD and 25 caregivers for Phase 1, of which 7 dyads (14 participants) participated in Phase 2. The drop-off in recruitment was due to unforeseen circumstances (the COVID-19 pandemics). We recruited participants and collected data between November 2018 and January 2020.

\section{Recruitment}

Our recruitment strategy was composed of several steps involving the FMPs and the research team (See online Additional file 1 for more information).

For Phase 1:

- At each FMP, a nurse was in charge of requesting the FPs a list of the potential participants who correspond to the eligibility criteria stated above. Then, the nurse called them to explain the project objective and their expected role and asked if they were willing to participate in our study. The nurse then shared the list of the participants that agreed to participate with the research team. As per ethics directives, the research team only received the list of those who agreed to participate.

After receiving the list from the FMPs of 32 PWD, a research assistant was in charge of contacting the potential participants to explain the project, their role as participants of the project, evaluate the PWD ability to consent, schedule a date for the consent form and the questionnaires for Phase 1.

Out of 32 PWD contacted, 29 agreed to participate in Phase 1 of our project. Of those, 25 had a caregiver present. All caregivers agreed to participate in phase 1.

For Phase 2:

- At the end of the appointment for Phase 1, the participants were asked if they were interested in being contacted for a semi-structured interview.

- The participants that agreed were contacted at another date for explaining the objective of Phase 2, evaluate the PWD ability to consent, and schedule a date of the interview.

Seven out of 17 dyads (PWD and caregiver) agreed to participate in the second phase. Reasons for refusal included change of residence (living outside Montreal), no longer interested in the study and impossibility of reaching them by phone.

\section{Data collection}

\section{Phase 1: Cross-sectional quantitative study}

We collected information on sociodemographic characteristics of the patients and their caregivers (age, gender, educational level, spoken language, relationship with the care recipient, (not) living with the care recipient).

To evaluate the PWD's cognition, we used the MMSE and MoCA tests [34]. To evaluate their needs, we used the Camberwell Assessment of Need for Elderly (CANE) for patients [35]; and the Carers' Needs Assessment for Dementia (CNA-D) for caregivers [36].

To assess behavioral disturbance, we used the Neuropsychiatric Inventory (NPI) [33, 34]. The quality of life was evaluated using the Quality of Life - Alzheimer's Disease scale (QOL-AD) [37]. See online Additional file 1 for more details on the tools.

All the questionnaires were available in English and French. The questionnaires were done by the second, third, and fourth author, between April 2019 and January 2020, at the place of preference of the participants. These authors were a nurse practitioner, and general practitioner, and a medical student, respectively. All of them have experience in research. We used the paper version of the questionnaires. This were then inputted into the database by the researcher who carried out the questionnaire.

\section{Phase 2: Qualitative descriptive study}

We carried out semi-structured qualitative interviews with PWD and their caregivers for exploring and understanding their experiences on services currently received at their FMP during the past 12 months, with special 
emphasis on dementia services, as well as the perceptions on those services for possible reasons for their met and unmet health and social care needs. The second, third, and fourth co-author conducted the interviews at the participants place of preference between April 2019 and January 2020 by pairs, depending on their availability. One of them was in charge of taking notes while the other facilitated the interview. The interviews were carried out either individually (one with the PWD and one with the caregiver) or together, depending on the preference of the participants. Interviews lasted between 11 minutes and 45 minutes, with an average of 28 minutes. Our semi-structured interview guide included questions about the beginning of their memory problems, their experience regarding their diagnostic process (including whether they received a diagnosis, by who and when), information received about the disease, resources available, and planning for the future (legal and financial advice, long-term care) as well as the questions on the unmet health and social needs highlighted by a patient or a caregiver in the quantitative phase to further explore possible causes and get the opinion on what could be done differently. Other questions included whether they had contact or not with a case manager and their experience with the care received at their clinic. Interviews were audio-recorded and transcribed verbatim.

\section{Data analysis}

Data from phase one was analyzed using descriptive statistics using RStudio (1.0.153). Data from phase 2 was analyzed independently by second and third co-authors using inductive thematic analysis [38] in NVivo 12 who then met to identify convergence and divergence among researchers. Themes were refined and divergences were solved by consensus. The results were then shared with the first author.

\section{Integration of the quantitative and qualitative studies}

Results from the quantitative and qualitative phases were compared and contrasted and ultimately interpreted together [39]. The integration of the results from both studies was done using a narrative discussion approach [39] to analyze the collected data to identify the commonalities and required actions [40]. This approach allowed us to understand the phenomenon in more depth. A second and third authors identified the common themes of the qualitative study and shared with the first author. After the discussion and finalizing the themes, all authors together matched the unmet needs from the quantitative study with the themes of the qualitative study to propose the possible solutions that could be implemented to improve their needs and expectations (Fig. 1).

\section{Results}

\section{Phase 1: Quantitative results}

Our sample was composed of 29 PWD with a mean age of 79.1 (10.3; 60-108) years and 25 informal caregivers with a mean age of $71.3(11.1 ; 41-90)$ years. The majority of PWD and caregivers had completed at least high school, and most of the participants were retired. Regarding the relationship of the dyads ( $n=25$ ), $80 \%$ of them were a couple, $16 \%$ were a children of the patient, and $4 \%$ were friends (Table 1 ).

Table 2 shows the overall results of PWD and caregivers' assesment tools. PWD were still in early stage of dementia with a mean MMSE score of $25.6(4.5$; 9-30) and mean MoCA of 21.3 (5.2; 8-28). PWD's quality of life was scored in average $37.8(5.7 ; 24-47)$ by the patient and $34.7(6.9 ; 19-48)$ by the caregivers (the maximum score is 52). The low scores of NPI (5.34) indicates mild behavioral disturbances among PWD.

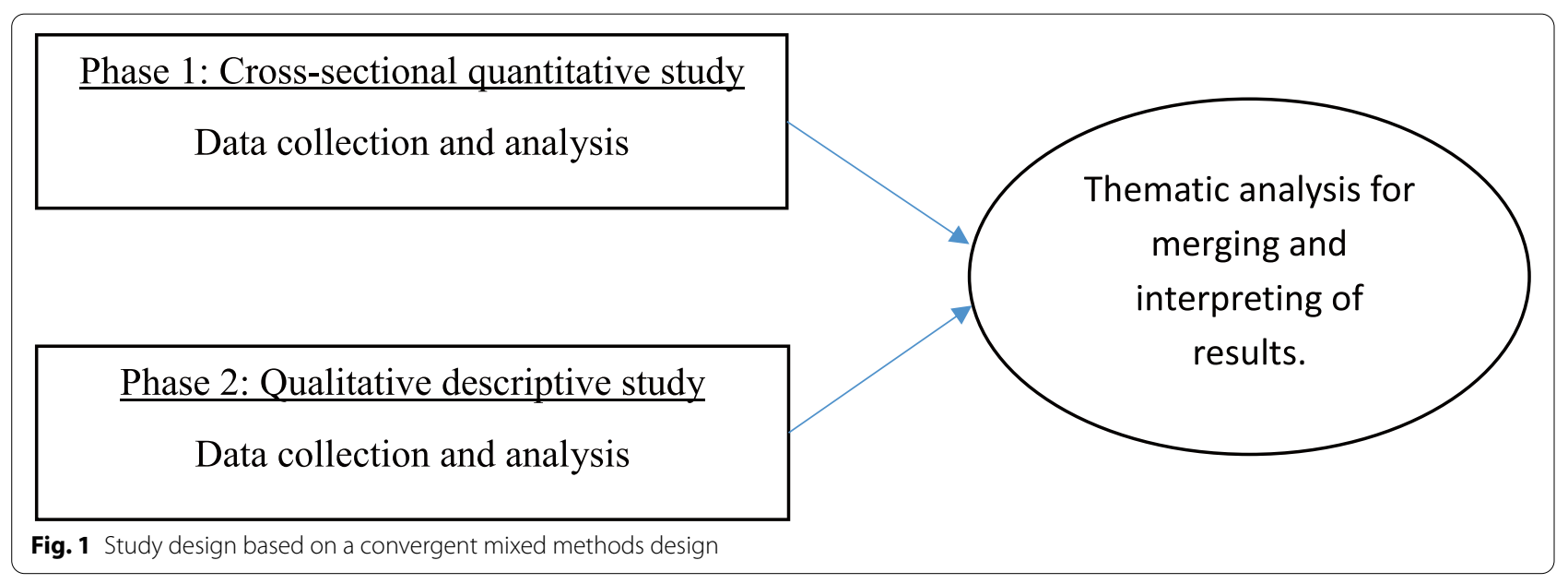


Table 1 Sociodemographic characteristics of PWD $(n=29)$ and their informal caregivers $(n=25)$

\begin{tabular}{lll}
\hline & PLWD (29) & Caregivers (25) \\
\hline Age (mean, SD, range) & $79.1(10.35 ; 60-108)$ & $71.3(11.1 ; 41-90)$ \\
Sex, male (number, \%) & $18(62,1 \%)$ & $4(16 \%)$ \\
Highest level of education completed (number, \%) & & $7(28 \%)$ \\
$\quad$ Below high school & $8.6 \%)$ & $7(28 \%)$ \\
High school - Apprenticeship & $11(38 \%)$ & $11(44 \%)$ \\
$\quad$ College, CEGEP*, University or above & $10(34.5 \%)$ & $18(72 \%)$ \\
Work activity (number, \%) & & $1(4 \%)$ \\
$\quad$ Retired & $28(96.6 \%)$ & $6(24 \%)$ \\
$\quad$ Working part-time & $0(0 \%)$ & $1(3.4 \%)$ \\
$\quad$ Working full-time & & $20(80 \%)$ \\
Relationship with patient (number, \%) & $4(16 \%)$ & $1(4 \%)$ \\
$\quad$ Couple & & \\
Parent-child & & \\
Other &
\end{tabular}

${ }^{*}$ CEGEP equivalent of the college in the Quebec education system

\section{Overall needs}

The mean total number of needs reported by the patients was 5.03 , of these 4.48 were met needs and 0.55 unmet needs. In contrast to the patients, the caregivers had only 0.52 met needs (3.16 unmet needs) (see Table 2).

\section{Specific patients needs}

PWD's self reported needs were in the following categories: memory, physical health, eyesight/hearing/

Table 2 Overall results of PWD and caregivers assessment $(n=29)$

\begin{tabular}{|c|c|c|c|}
\hline Patient's memory issues & Mean & SD & Range \\
\hline Mini-Mental State Examination (MMSE) & 25.66 & 4.56 & $9-30$ \\
\hline Montreal Cognitive Assessment (MoCA) & 21.31 & 5.21 & $8-28$ \\
\hline \multicolumn{4}{|l|}{ NPI } \\
\hline 12 item NPI score & 5.34 & 6.60 & $0-20$ \\
\hline \multicolumn{4}{|l|}{ QOL-AD } \\
\hline Scored by patient $(\mathrm{n}=29)$ & 37.83 & 5.79 & $24-47$ \\
\hline Scored by caregiver $(n=25)$ & 34.76 & 6.95 & $19-48$ \\
\hline \multicolumn{4}{|l|}{ CANE } \\
\hline Patient-reported met needs $(n=29)$ & 4,48 & 2,52 & $2-11$ \\
\hline Patient-reported unmet needs $(n=29)$ & 0,55 & 0,91 & $0-4$ \\
\hline Patient-reported total needs $(n=29)$ & 5,03 & 2,56 & $2-12$ \\
\hline Caregiver-reported met needs $(n=25)$ & 5,08 & 2,55 & $2-11$ \\
\hline Caregiver -reported unmet needs $(n=25)$ & 0,80 & 0,87 & $0-3$ \\
\hline Caregiver -reported total needs $(n=25)$ & 5,88 & 2,77 & $2-12$ \\
\hline \multicolumn{4}{|l|}{ CNA-D } \\
\hline $\begin{array}{l}\text { Caregiver reported number of moderate or } \\
\text { serious problems }(n=25)\end{array}$ & 3.12 & 2.35 & $0-7$ \\
\hline Caregiver reported meet needs $(n=25)$ & 0.52 & 0.77 & $0-2$ \\
\hline Caregiver reported unmet needs $(n=25)$ & 3.16 & 3.20 & $0-10$ \\
\hline
\end{tabular}

communication, drugs, looking after home, money/ budgeting as the main needs (figure 2 and 3 of online Additional file 1). However, most of these needs were met except for memory that was frequently rated by pairs of PWD and caregivers as unmet need. This was also reflected in the rating of the needs by a researcher (figure 4 of online Additional file 1).

\section{Specific caregivers needs}

The needs of caregivers were lack of the emotional support, counselling, psychoeducation and psychotherapy as well as social worker support, printed information on dementia/treatment/services (figure 5, 6, 7 and 8 of online Additional file 1). They also rated high the frequency of physical and psychiatric illnesses but they were well addressed (figure 8 of online Additional file 1).

\section{Phase 2: Qualitative results}

We conducted the interviews with seven pairs of PWD and caregivers. We identified three broad categories: attitude towards the memory decline, perception of the community health services and perception of the family medicine practice.

\section{Attitude towards the memory decline}

Both the patient and the caregiver noted a gradual decline of PWD's memory that they frequently attributed to age. Despite having mentioned this tothe FPs, it was not often taken into account. However, the FPs would start an evaluation and the required referrals to specialized services when the memory decline became more obvious and interfering with the patient's daily life: 
"It took one year until the diagnosis [...] I forget the keys, things in the shopping ..." (patient)

Regarding the memory decline and diagnosis, participants indicated that they felt they did not receive enough information from the FP regarding this issue which led to lack of knowledge on the diagnosis.

"The last thing the doctor said, was that (the patient) had an aging of the brain. He had seen the scan, he had done all that, and he found it was the aging of the brain [...] I don't know more than that. [The doctor] has not given us a diagnosis" (caregiver)

\section{Perception of the community health services}

PWD and their caregivers often did not receive timely access to the community services when required, plus it was not tailored to their specific expectations and needs. In adddition, the regular change of the personnel who provided in-home services was another issue that required PWD and their caregivers to constantly adapt.

"[I] would like to have written material on the services" (caregiver)

Those participants who had used community health services, had a case manager, who was in close communication with the caregiver. In one specific example, the case manager supported the caregiver with multiple changes of the home care staff since they were not trained to provide the appropriate care:

"Let them send me a man who can take care of my husband. What are they sending me, a woman, but every time, it stresses me out [...] I don't understand why they send incompetent people?"

\section{Perception of the family medicine practice}

In contrast to the community services, PWD and their caregivers were in general satisfied with their FPs and nurses. They especially appreciated the FMPs' nurses who spend more time with them and listen to their concerns. They also expressed a desire to have a more permanent doctor in the FMP as they found it difficult that their family medicine resident changed every two years.

\section{"[The nurse] would have more time in her hands than the doctor does. The doctor, I notice that she is running back and forth, back and forth. The nurse doesn't do that." (caregiver)}

Some participants indicated their family phsycian referred them for cognitive testing but did not follow-up on the results. Most of the participants stated that they needed more information regarding the prognosis, management at home, and how to access support services (including financial support services). If they had this information, it came from either a family member who worked in a health-related profession, or from other sources, such as a bank worker, but not from their primary care provider.

\section{Integration of quantitative and qualitative results (mixed methods integration)}

The results integration enhanced our understanding of PWD and caregivers' expectations in the context of the provincial Plan:

- The patients and their caregivers would like to have a contact person in the clinic, preferably a nurse

- The caregivers would like to know the diagnosis early on

- The caregivers would like to have a written care plan

- The caregivers would like to have more attention to their own emotionnal distress

\section{Discussion}

Our empirical study describes the prevalence of met and unmet needs of PWD and their caregivers in the context of the Quebec Alzheimer plan. A study of the impact of the Quebec Alzheimer plan found that the evaluation of patients' and caregivers' overall needs were overlooked in more than $40 \%$ of the cases [27]. To evaluate met and unmet needs, we conducted a comprehensive assessement of the needs of PWD and their caregivers (quantitaive study) and then followed up by exploring and appreciating the experiences of the participants (qualitative study).

PWD rated their met needs highly (4.48) in contrast to their caregivers (0.52). A fewer unmet needs reported by PWD could be due to poor awareness of the problems or different priorities from their caregivers [41-45].

While our study confirms the findings of other studies on the most common unmet needs of the patients (e.g., information, memory) [46] and caregivers (e.g., information, caregiver burden) [46, 47], it also demostrated that the participants were satisfied with access to care and the medical services received in the primary care practices. Nontheless, our study shows that there are less unmet needs for PWD and caregivers compared to studies in other regions, such as the United States (most commont unmet needs were in the domains of safety and general care, and for caregivers, in the domains of referrals and education) [48, 
49], China (unmet needs in the domains of social and environmental areas) [50] and Europe (unmet needs for PWD mainly in the social domain) [51]. The PWD and their caregivers expressed the confidence in their FPs but were open to the alternative such as nurse practitioners who are more available.

Caregivers often reported lack of the emotional support and counselling. While the community services to support the caregivers exist, this particular need continues to be prevalent $[45,52]$. The explanation could be that frequently the caregivers opt to not use the services due to their unsuitability to their expectations [41]. Moreover, often a caregiver has FP different from the patient that adds a complexity to a comprehensive assessement of their needs.

Participants voiced their concerns about the change of their treating physicians (physician-residents) every 2 years that creates symptoms of uncertainty and anxiety [53]. However, given this reality of change every 2 years of the physician-residents, the participants were open to the idea that one person in the team can support the continuity such as a nurse clincian or practitioner [54].

The turnover of the personnel in the community services is another concern. The home care services should improve the continuity of homecare services such as to assign the same provider to the patients and their caregivers and to ensure the collaboration and good communication between family caregivers and staff from home services [55]. This can promote more consistency on patient centred care and more importantly, care based on a trusting long-term relationship.

Thus, our study provides a rich description of the needs of PWD and their caregivers that are either met partially or not at all. We would like to provide the following recommendations based on the voices of the participants:

- The family medicine practice should have a nurse practitioner as a key contact person for PWD and their caregivers. While the residents change in the teaching family practice every two years, the nurse practitioner could play a significant role in the continuty of care.

- The caregiver should receive a written information on the diagnosis, management, prognosis and available community services.

- The caregivers should have a separate appointment for an assessment of their needs.

- The psychological services of the community should extend their programs to caregivers support as well as to better understand and meet their expectations.
- The community services should focus on the recrutiment of personnel for permanent positions and assign them to the same patient-caregiver dyad.

Further research is needed to explore the needs of PWD depending on the stage of the disease, care received in the routine primary care vs university associated teaching facilities.

\section{Limitations}

The main limitation of our study is the sample size. Due to unforseen circumstances (the COVID-19 pandemic) we were only able to recruit a limited number of dyads. Due to the restraints imposed by certain ethics committee on the recruitement of the vulnerable patients (in our case, patients with dementia), the recruitement strategy could consider local Alzheimer chapters. Given the sample size, we were not able to identify the needs according to the disease stage. Future studies should look at the differences in needs across the different stages and the evolution of the disease. However, the qualitative part of the study showed the saturation of the data across the clinical sites despite the small sample of the participants. Interviewing PWD and their caregivers together could omit the nuances in comparison to the individual interviews.

In terms of the study design, a quasi-experimental study on the needs of the patiens could be considered. Unfortunately, the Plan has already been implemented in all university-associated primary care unites to conduct a case-control study.

Our study focussed on the needs of patients with already established dementia diagnosis. Future studies could evaluate the needs of patients prior to the established diagnosis in primary care.

Another limitation is that the family medicine practices were the teaching sites that could limit the extrapolation of the results to other non-teaching sites.

\section{Conclusions}

The Quebec Alzheimer plan with its focus on the involvement of FP and nurses in the primary care practices demostrated an overall success to meet the health needs of this vulnerable population. Our findings emphasize the importance to further tailor community services to better address the individual needs of PWD and their caregivers (e.g., a nurse as a contact person in the family medicine practice, the same healthcare provider of home care services). 


\section{Supplementary Information}

The online version contains supplementary material available at https://doi. org/10.1186/s12875-021-01528-3.

\section{Additional file 1}

\section{Acknowledgements}

We would like to thank all patients and their caregivers, family physicians of the family medicine practice (Herzl clinic, Village de Santé, Faubourg). We would also like to thank Nadia Sourial for her assistance with the sample size calculation. We also would like to thank the family physicians (Dr. Ben Albright and Dr. Miriam Abdelnour) for the feedback on the draft of the article.

\section{Authors' contributions}

Vladimir Khanassov was in charge of the conception and design, analysis and synthesis, interpretation of the results, and first draft of the article and final version. Laura Rojas-Rozo, Rosa Sourial, Martin Yang participated in data collection, analysis and synthesis, and the draft of the article. Isabelle Vedel was involved in conception, design and revision of the article. All authors approved the content of the manuscript.

\section{Funding}

This research was funded by the Fonds du Recherche du Québec - Santé (FRQS) with the Clinician Researcher Junior 1 Award given to Dr. Vladimir Khanassov and the Canadian Institutes of Health Research (CIHR) Planning and Dissemination Grant -Institute of Community Support, the Québec Réseau-1 research grant.

\section{Availability of data and materials}

The datasets used and/or analysed during the current study available from the corresponding author on reasonable request.

\section{Declarations}

\section{Ethics approval and consent to participate}

This study was reviewed and approved by the West-Central Montreal Health's First-Line/Psychosocial and Geriatrics (FLP) Research Ethics Committee (CODIM FLP REC) (Project MP-05-2019-1462). All individuals participating in our study read and signed an informed consent form. All methods were carried out in accordance to relevant guidelines.

\section{Consent for publication}

N/A

\section{Competing interests}

The authors declare that they have no competing interests.

\section{Author details}

${ }^{1}$ Herzl Clinic, Jewish General Hospital and Department of Family Medicine, McGill University, Montreal, Canada. ${ }^{2}$ Lady Davis Institute for Medical Research, Jewish General Hospital, Montreal, Canada. ${ }^{3}$ Department of Family Medicine, McGill University, Montreal, Canada.

Received: 11 March 2021 Accepted: 18 August 2021

Published online: 15 September 2021

\section{References}

1. World Health Organization. Dementia A Public Health Priority. 2012.

2. World Health Organization. The epidemiology and impact of dementia: current state and future trends. 2015.

3. Rubinstein E, Duggan C, Van Landingham B, Thompson D, Warburton W. WISH Dementia Forum. A call to action. The global response to dementia through policy innovation; 2015
4. Khanassov V, Vedel I. Family Physician-Case Manager Collaboration and Needs of Patients With Dementia and Their Caregivers: A Systematic Mixed Studies Review. Ann Fam Med. 2016;14(2):166-77.

5. Moore A, Frank C, Chambers LW. Role of the family physician in dementia care. Can Fam Physician. 2018;64(10):717.

6. Zwingmann I, Michalowsky B, Esser A, Kaczynski A, Monsees J, Keller A, et al. Identifying Unmet Needs of Family Dementia Caregivers: Results of the Baseline Assessment of a Cluster-Randomized Controlled Intervention Trial. J Alzheimers Dis. 2019;67(2):527-39.

7. Riedel O, Klotsche J, Wittchen HU. Overlooking Informal Dementia Caregivers' Burden. Res Gerontol Nurs. 2016;9(4):167-74.

8. Waldemar G, Phung K, Burns A, Georges J, Hansen F, lliffe S, et al. Access to diagnostic evaluation and treatment for dementia in Europe. Int J Geriatric Psychiatry. 2007;22(1):47-54.

9. Galvin JE, Valois $\mathrm{L}$, Zweig Y. Collaborative transdisciplinary team approach for dementia care. Neurodegener Dis Manag. 2014;4(6):455-69.

10. Reilly S, Miranda-Castillo C, Malouf R, Hoe J, Toot S, Challis D, et al. Case management approaches to home support for people with dementia. Cochrane Database Syst Rev. 2015;1 (1):Cd008345.

11. Thyrian JR, Fiß T, Dreier A, Böwing G, Angelow A, Lueke S, et al. Life- and person-centred help in Mecklenburg-Western Pomerania, Germany (DelpHi): study protocol for a randomised controlled trial. Trials. 2012;13:56.

12. Callahan CM, Boustani MA, Weiner M, Beck RA, Livin LR, Kellams JJ, et al. Implementing dementia care models in primary care settings: The Aging Brain Care Medical Home. Aging Ment Health. 2011;15(1):5-12.

13. LaMantia MA, Alder CA, Callahan CM, Gao S, French DD, Austrom MG, et al. The Aging Brain Care Medical Home: Preliminary Data. J Am Geriatr Soc. 2015;63(6):1209-13.

14. Iliffe S, Waugh A, Poole M, Bamford C, Brittain K, Chew-Graham C, et al. The effectiveness of collaborative care for people with memory problems in primary care: results of the CAREDEM case management modelling and feasibility study. Health Technol Assess. 2014;18(52):1-148.

15. Dreier-Wolfgramm A, Michalowsky B, Austrom MG, van der Marck MA, lliffe S, Alder C, et al. Dementia care management in primary care : Current collaborative care models and the case for interprofessional education. Z Gerontol Geriatr. 2017;50(Suppl 2):68-77.

16. Moore A, Patterson C, Lee L, Vedel I, Bergman H. Canadian Consensus Conference on the D, et al. Fourth Canadian Consensus Conference on the Diagnosis and Treatment of Dementia: recommendations for family physicians. Can Fam Physician. 2014;60(5):433-8.

17. Ismail Z, Black SE, Camicioli R, Chertkow H, Herrmann N, Laforce R Jr, Montero-Odasso M, Rockwood K, Rosa-Neto P, Seitz D, Sivananthan S, Smith EE, Soucy JP, Vedel I, Gauthier S, CCCDTD5 Participants. Recommendations of the 5th Canadian Consensus Conference on the diagnosis and treatment of dementia. Alzheimers Dement. 2020;16(8):1182-95.

18. Gress S, Baan CA, Calnan M, Dedeu T, Groenewegen P, Howson H, et al. Co-ordination and management of chronic conditions in Europe: the role of primary care--position paper of the European Forum for Primary Care. Qual Prim Care. 2009;17(1):75-86.

19. Institute of Medicine. Living well with chronic illness: a call for public health action. Washington, DC: The National Academies Press; 2012.

20. Wortmann M. Dementia: a global health priority - highlights from an ADI and World Health Organization report. Alzheimer's Res Ther. 2012;4(5):40.

21. Koch T, lliffe S. Dementia diagnosis and management: a narrative review of changing practice. Br J Gen Pract. 201 1;61(589):e513-25.

22. Verkade P, van Meijel B, Brink C, van Os-Medendorp H, Koekkoek B, Francke A. Delphi research exploring essential components and preconditions for case management in people with dementia. BMC Geriatrics. 2010;10:54.

23. Knopman D, Donohue J, Gutterman E. Patterns of care in the early stages of Alzheimer's disease: impediments to timely diagnosis. J Am Geriatrics Soc. 2000:48(3):300-4.

24. Lai C, Cipriani M, Renzi A, Luciani M, Lombardo L, Aceto P. The Effects of the Perception of Being Recognized by Patients With Alzheimer Disease on a Caregiver's Burden and Psychophysical Health. Am J Hospice Palliative Care. 2018:35(9):1188-94.

25. Agence de la santé et des services sociaux de Montréal. Le modèle montréalais de prise en charge : évaluation de l'implantation des groupes de médecine de famille (GMF) et des cliniques-réseau (CR). Montréal, QC; 2010.

26. Bergman H. Report of the Committee of Experts for the Development of an Action Plan on Alzheimer's Disease and Related Disorders; 2009. 
27. Vedel I, Sourial N, Arsenault-Lapierre G, Godard-Sebillotte C, Bergman H. Impact of the Quebec Alzheimer Plan on the detection and management of Alzheimer disease and other neurocognitive disorders in primary health care: a retrospective study. CMAJ Open. 2019;7(2):E391-E8.

28. Penfold RB, Zhang F. Use of interrupted time series analysis in evaluating health care quality improvements. Acad Pediatrics. 2013;13(6 Suppl):S38-44.

29. INTERDISCIPLINARY CLINICAL PROCESS - Family Medicine Group (FMG) OUTREACH SERVICES MILD OR MAJOR NEUROCOGNITIVE DISORDERS (mNCD or MNCD) - DIAGNOSIS COMPONENT (1)2020 May 12, 2021. Available from: https://www.mcgill.ca/familymed/files/familymed/interdisci plinary_clinical_process_diagnostic.pdf. Accessed 4 Sept 2021.

30. INTERDISCIPLINARY CLINICAL PROCESS - FAMILY MEDICINE GROUP (FMG) OUTREACH SERVICES MILD OR MAJOR NEUROCOGNITIVE DISORDERS (mNCDor MNCD) - FOLLOW-UP COMPONENT (2)2020 May 12, 2021. Available from: https://www.mcgill.ca/familymed/files/familymed/ interdisciplinary_clinical_process_follow-up.pdf. Accessed 4 Sept 2021.

31. Creswell J, Clark V. Designing and Conducting Mixed Methods Research CA: Sage; 2011.

32. Margaret C, Glenda C, Fiona H. How to use web-based information to support people with dementia. Nurs Older People. 2012;24(9):14-20.

33. Cummings JL, Mega M, Gray K, Rosenberg-Thompson S, Carusi DA, Gornbein J. The Neuropsychiatric Inventory: comprehensive assessment of psychopathology in dementia. Neurology. 1994;44(12):2308-14.

34. Moniz-Cook E, Vernooij-Dassen M, Woods R, Verhey F, Chattat R, De Vugt $M$, et al. A European consensus on outcome measures for psychosocial intervention research in dementia care. Aging Ment Health. 2008;12(1):14-29.

35. Reynolds T, Thornicroft G, Abas M, Woods B, Hoe J, Leese M, et al. Camberwell Assessment of Need for the Elderly (CANE). Development, validity and reliability. Br J Psychiatry. 2000;176:444-52.

36. Wancata J, Krautgartner M, Berner J, Alexandrowicz R, Unger A, Kaiser G, et al. The Carers' Needs Assessment for Dementia (CNA-D): development, validity and reliability. Int Psychogeriatr. 2005;17(3):393-406.

37. Logsdon RG, Gibbons LE, McCurry SM, Teri L. Assessing quality of life in older adults with cognitive impairment. Psychosom Med. 2002;64(3):510-9.

38. Boyatzis RE. Transforming qualitative information: Thematic analysis and code development: SAGE; 1998.

39. Creswell JW, Clark VLP. Designing and conducting mixed methods research: Sage publications; 2017.

40. Sandelowski M, Voils Cl, Barroso J. Defining and Designing Mixed Research Synthesis Studies. Res Sch. 2006;13(1):29.

41. Orrell M, Hancock GA, Liyanage KC, Woods B, Challis D, Hoe J. The needs of people with dementia in care homes: the perspectives of users, staff and family caregivers. Int Psychogeriatr. 2008;20(5):941-51.

42. van der Roest HG, Meiland FJ, Comijs HC, Derksen E, Jansen AP, van Hout $H P$, et al. What do community-dwelling people with dementia need? A survey of those who are known to care and welfare services. Int Psychogeriatrics. 2009;21(5):949-65.
43. Hancock GA, Reynolds T, Woods B, Thornicroft G, Orrell M. The needs of older people with mental health problems according to the user, the carer, and the staff. Int J Geriatric Psychiatry. 2003;18(9):803-11.

44. Trigg $R$, Watts $S$, Jones $R$, Tod A. Predictors of quality of life ratings from persons with dementia: the role of insight. Int J Geriatric Psychiatry. 2011;26(1):83-91.

45. Miranda-Castillo C, Woods B, Orrell M. The needs of people with dementia living at home from user, caregiver and professional perspectives: a cross-sectional survey. BMC Health Serv Res. 2013;13(1):43.

46. Kerpershoek L, de Vugt M, Wolfs C, Woods B, Jelley H, Orrell M, et al. Needs and quality of life of people with middle-stage dementia and their family carers from the European Actifcare study. When informal care alone may not suffice. Aging Ment Health. 2018;22(7):897-902.

47. Jennings LA, Reuben DB, Evertson LC, Serrano KS, Ercoli L, Grill J, et al. Unmet needs of caregivers of individuals referred to a dementia care program. J Am Geriatr Soc. 2015;63(2):282-9.

48. Black BS, Johnston D, Rabins PV, Morrison A, Lyketsos C, Samus QM. Unmet Needs of Community-Residing Persons with Dementia and Their Informal Caregivers: Findings from the Maximizing Independence at Home Study. J Am Geriatrics Soc. 2013;61(12):2087-95.

49. Black BS, Johnston D, Leoutsakos J, Reuland M, Kelly J, Amjad H, et al. Unmet needs in community-living persons with dementia are common, often non-medical and related to patient and caregiver characteristics. Int Psychogeriatr. 2019;31(11):1643-54.

50. Zhang J, Xu X, Yang L, Wang J. Met and unmet care needs of homeliving people with dementia in China: An observational study using the Camberwell Assessment of Need for the Elderly. Geriatr Gerontol Int. 2021;21(1):102-7.

51. Janssen N, Handels RL, Köhler S, Gonçalves-Pereira M, Marques MJ, Irving K, et al. Profiles of Met and Unmet Needs in People with Dementia According to Caregivers' Perspective: Results from a European Multicenter Study. J Am Med Dir Assoc. 2020;21(11):1609-16 e1.

52. Miranda-Castillo C, Woods B, Orrell M. People with dementia living alone: what are their needs and what kind of support are they receiving? Int Psychogeriatrics. 2010;22(4):607-17.

53. Riley GA, Evans L, Oyebode JR. Relationship continuity and emotional well-being in spouses of people with dementia. Aging Ment Health. 2018:22(3):299-305.

54. Fortinsky RH, Delaney C, Harel O, Pasquale K, Schjavland E, Lynch J, et al. Results and lessons learned from a nurse practitioner-guided dementia care intervention for primary care patients and their family caregivers. Res Gerontol Nurs. 2014;7(3):126-37.

55. Larsen LS, Normann HK, Hamran T. Continuity of home-based care for persons with dementia from formal and family caregivers' perspective. Dementia (London). 2019;18(3):846-63.

\section{Publisher's Note}

Springer Nature remains neutral with regard to jurisdictional claims in published maps and institutional affiliations.

\footnotetext{
Ready to submit your research? Choose BMC and benefit from:

- fast, convenient online submission

- thorough peer review by experienced researchers in your field

- rapid publication on acceptance

- support for research data, including large and complex data types

- gold Open Access which fosters wider collaboration and increased citations

- maximum visibility for your research: over $100 \mathrm{M}$ website views per year
}

At BMC, research is always in progress.

Learn more biomedcentral.com/submissions 